\title{
Serum Resistin as a Novel Marker of Erythropoietin Resistance in Nondiabetic Patients on Hemodialysis
}

\author{
Jae Hyun Chang, ${ }^{1,2}$ Ji Yong Jung, ${ }^{1,2}$ Hyun Hee Lee, ${ }^{1,2}$ Wookyung Chung, ${ }^{1,2}$ \\ Kwon-Wook Joo ${ }^{3}$ and Sejoong Kim ${ }^{1,2}$ \\ ${ }^{1}$ Department of Internal Medicine, Gachon University of Medicine and Science, Incheon, Korea \\ ${ }^{2}$ Laboratory of Molecular Nephrology, Gachon University of Medicine and Science, Incheon, Korea \\ ${ }^{3}$ Department of Internal Medicine, Seoul National University College of Medicine, Seoul, Korea
}

\begin{abstract}
The use of higher erythropoietin (EPO) doses is associated with an increased risk of an adverse outcome and increased mortality in patients with renal failure. Resistin is related to heart disease, and may contribute to an increased atherosclerotic risk. We hypothesized that a link between resistin and EPO responsiveness may exist. We therefore investigated the relationship between resistin and the EPO resistance index (ERI) in nondiabetic hemodialysis (HD) patients. Fifty-seven patients enrolled in the study underwent $\mathrm{HD}$ for $\geq 3$ months and intravenous EPO therapy to maintain a target hemoglobin $(\mathrm{Hb})$ level of $11.0 \mathrm{~g} / \mathrm{dl}$. The ERI was defined as the weekly EPO dose per unit $\mathrm{Hb}$ per body weight. The mean patient age was $52.6 \pm 11.9$ years and the mean time on dialysis was $4.9 \pm 4.4$ years. Serum $\mathrm{Hb}$ and ERI were $10.4 \pm 0.7 \mathrm{~g} / \mathrm{dl}$, and $13.3 \pm 7.0(\mathrm{IU} / \mathrm{kg} / \mathrm{week} / \mathrm{g} / \mathrm{dl})$, respectively. Serum resistin levels were $23.6 \pm 9.3 \mu \mathrm{g} / \mathrm{L}$. EPO resistance is associated with low body mass index (BMI) (coefficient $\beta=-0.393, p=0.002$ ) and with high serum resistin levels (coefficient $\beta=0.332, p=0.018$ ). According to a multiple regression analysis, the serum resistin level was a significant independent factor related to EPO resistance $(p=0.017)$. The results suggest that serum resistin levels reflect EPO responsiveness in nondiabetic HD patients. Resistin may therefore be considered as a new marker of EPO responsiveness in HD patients.
\end{abstract}

Key words: adipokine; anemia; erythropoietin responsiveness; hemodialysis; resistin

Tohoku J. Exp. Med., 2011, 224 (4), 281-285. (C) 2011 Tohoku University Medical Press

Anemia is common in patients with chronic kidney disease and is associated with a higher risk of mortality from cardiovascular disease. Recombinant human erythropoietin (EPO) has been used in chronic hemodialysis (HD) patients to treat anemia and to improve the quality of life. However, marked variability exists in patient sensitivity to EPO, with one study reporting up to a tenfold variability in dose requirements to achieve anemia correction (Costa et al. 2008b). The use of higher EPO doses is reported to be associated with increased mortality, even when hemoglobin $\mathrm{Hb}$ levels within the target range were achieved (Zhang et al. 2004; Regidor et al. 2006). EPO responsiveness and the achieved $\mathrm{Hb}$ values are strong predictors of mortality risk (Kilpatrick et al. 2008).

Adipocytokines are soluble mediators produced by adipocytes that may provide the link between the response of adipose tissue and the numerous physiological and pathological processes (Lago et al. 2007). Resistin, a 108amino acid peptide hormone with a molecular weight of $12.5 \mathrm{kDa}$, is produced exclusively by mouse adipocytes and regulates glucose homeostasis (Steppan et al. 2001).
Recent studies have shown that resistin is related to heart disease in patients with end-stage renal disease (ESRD) (Diez et al. 2005), and may contribute to an increased atherosclerotic risk through modulating the activity of endothelial cells (Cohen and Horl 2009). We hypothesized that a link between resistin and EPO responsiveness may exist. We therefore investigated the relationship between resistin and EPO responsiveness in HD patients.

\section{Subjects and Methods}

Subjects

The study began in March 2009 and ended in May 2009. All patients enrolled in the study underwent maintenance HD at the dialysis unit of Gachon University Gil Hospital, Incheon, Korea. Selected participants met the following inclusion criteria: dialysis therapy for $\geq 3$ months, age $\geq 18$ years, and provision of informed consent. Exclusion criteria included subjects who expressed doubts regarding study enrollment; diabetes mellitus; acute inflammation within the previous 3 months; severe heart failure (New York Heart Association class IV); acute myocardial infarction, coronary intervention, or coronary artery bypass graft within the previous 3 months; and cardiac

Received May 9, 2011; revision accepted for publication July 7, 2011. doi: 10.1620/tjem.224.281

Correspondence: Sejoong Kim, M.D., Ph.D., Department of Internal Medicine, Gachon University Gil Hospital, 1198, Guwol-dong, Namdong-gu, Incheon, 405-760, South Korea.

e-mail: imsejoong@hanmail.net 
valvular disease requiring surgery.

A total of 57 patients were enrolled in the study. The mean patient age was $52.6 \pm 11.9$ years and $53 \%$ were male. The mean patient time on dialysis was $4.9 \pm 4.4$ years. The causes of ESRD were hypertension in 12 patients $(21.0 \%)$, which was followed by glomerulonephritis in $7(12.3 \%)$, other causes in $5(8.8 \%)$, and unknown causes in $33(57.9 \%)$ patients. Thirty-three patients $(57.9 \%)$ received angiotensin-converting enzyme inhibitors or angiotensin receptor blockers (Table 1). All the patients were dialyzed with biocompatible membranes (F5 or F6; Fresenius Medical Care AG, Bad Homberg, Germany) three times per week using Fresenius $4008 \mathrm{H}$ (Fresenius Medical Care AG).

All patients provided written informed consent, and the study protocol was approved by the ethics committee of the institutional review board of Gachon University Gil Hospital.

\section{Study protocol}

Patients in this study received EPO (erythropoietin- $\alpha$; CJ Pharma, Seoul, Korea) intravenously at a frequency ranging from twice to thrice weekly according to the Kidney Disease Outcomes Quality Initiative guidelines. The EPO dose was titrated with the aim of maintaining a target $\mathrm{Hb}$ level of $11.0 \mathrm{~g} / \mathrm{dl}$. Patients on EPO also received $160 \mathrm{mg}$ of oral ferrous sulfate as an iron supplement to maintain serum ferritin at $>100 \mathrm{ng} / \mathrm{ml}$ and transferrin saturation (TSAT) at $>20 \%$. Intravenous ferric hydroxide was administered as a repletive 100-mg dose for 10 consecutive HD treatments, when the patient's TSAT was $<20 \%$ or the serum ferritin concentration was $<100 \mathrm{ng} / \mathrm{ml}$. Patients with TSAT $\geq 50 \%$ and serum ferritin of $\geq 800$ $\mathrm{ng} / \mathrm{ml}$ did not receive iron supplementation. The EPO resistance index (ERI) was calculated as the ratio between the weight-adjusted EPO dose (IU/kg/week) and $\mathrm{Hb}$ (g/dl) (Kanbay et al. 2010).

\section{Measurement of plasma resistin, adiponectin and IL-6}

All parameters were measured in patients starting at the midweek dialysis session. The acquired serum samples were centrifuged, and the supernatants were withdrawn and immediately frozen at $-70^{\circ} \mathrm{C}$ for later analysis. Resistin and adiponectin levels were determined using the Bio-Plex Pro human diabetes assays (Bio-Rad Laboratories, Hercules, CA, USA), and serum interleukin (IL)-6 con-

Table 1. Clinical characteristics of the patients.

\begin{tabular}{lc}
\hline Age (year) & $52.6 \pm 11.9$ \\
Sex (Males/Females) & $30 / 27$ \\
Dialysis duration (year) & $4.9 \pm 4.4$ \\
Causes of ESRD & \\
Hypertension & 12 \\
Glomerulonephritis & 7 \\
Others & 5 \\
Unknown & 33 \\
BMI (kg/m ${ }^{2}$ ) & $21.0 \pm 3.7$ \\
History of congestive heart failure & 3 \\
History of ischemic heart disease & 5 \\
History of ACEi or ARB & 33 \\
\hline
\end{tabular}

ESRD, end stage renal disease; BMI, body mass index; ACEi, Angiotensin-converting enzyme inhibitors; ARB, angiotensin receptor blockers. centrations using the Bio-Plex multiplex cytokine assay (Bio-Rad Laboratories).

\section{Statistical methods}

The results are reported as means \pm S.D. or number (percentage). The data were analyzed using SPSS 12.0 for Windows (SPSS Inc., Chicago, IL, USA). Categorical variables were compared with the chi-square test and continuous variables with the Student's $t$-test or Wilcoxon test. Univariate regression was used to determine correlations between ERI and other variables. Due to their skewed distribution, C-reactive protein (CRP), IL-6, adiponectin, and resistin values were $\log$ transformed. To identify factors associated with EPO responsiveness, all variables with $P$-values of $<0.10$ were entered into a multivariable linear regression analysis. Values of $p<0.05$ were deemed to be statistically significant.

\section{Results}

Serum $\mathrm{Hb}$, ferritin, total cholesterol, and parathyroid hormone levels were $10.4 \pm 0.7 \mathrm{~g} / \mathrm{dl}, 313 \pm 266 \mathrm{ng} / \mathrm{ml}, 156$ $\pm 34 \mathrm{mg} / \mathrm{dl}$ and $280 \pm 363 \mathrm{pg} / \mathrm{ml}$, respectively. The singlepool Kt/V and normalized protein nitrogen appearance rate were $1.54 \pm 0.30$, and $1.10 \pm 0.28 \mathrm{~g} / \mathrm{kg} /$ day, respectively. Serum resistin and adiponectin levels were $23.6 \pm 9.3 \mu \mathrm{g} / \mathrm{L}$ and $75.5 \pm 12.6 \mathrm{mg} / \mathrm{L}$, respectively. These levels in our HD patients were higher than those of healthy subjects (serum resistin $5.8 \pm 1.7 \mu \mathrm{g} / \mathrm{L}$ and adiponectin $6.7 \pm 3.8 \mathrm{mg} / \mathrm{L}$ ), as reported by other investigators (Ziegelmeier et al. 2008). The EPO dose and ERI were 6,982 $\pm 3,299 \mathrm{IU} /$ week and

Table 2. Biochemical characteristics of the patients.

\begin{tabular}{lc}
\hline Hemoglobin (g/dl) & $10.4 \pm 0.7$ \\
Hematocrit (\%) & $31.0 \pm 2.1$ \\
Ferritin (ng/ml) & $313 \pm 266$ \\
TSAT (\%) & $26.0 \pm 11.9$ \\
Albumin (g/dl) & $3.8 \pm 0.4$ \\
Calcium (mg/dl) & $8.3 \pm 0.6$ \\
Phosphorus (mg/dl) & $5.1 \pm 1.7$ \\
PTH (pg/ml) & $280 \pm 363$ \\
Total cholesterol (mg/dl) & $156 \pm 34$ \\
Triglyceride (mg/dl) & $120 \pm 67$ \\
HDL-cholesterol (mg/dl) & $44 \pm 18$ \\
spKt/V & $1.54 \pm 0.30$ \\
URR (\%) & $71.5 \pm 6.0$ \\
nPNA (g/kg/day) & $1.10 \pm 0.28$ \\
Resistin (ug/L) & $23.6 \pm 9.3$ \\
Adiponectin (mg/L) & $75.5 \pm 12.6$ \\
CRP (mg/L) & $7.0 \pm 5.0$ \\
Interleukin-6 (ng/mL) & $5.6 \pm 6.0$ \\
Erythropoietin (IU/week) & $6,982 \pm 3,299$ \\
ERI (IU/kg/week/g/dl) & $13.3 \pm 7.0$ \\
\hline
\end{tabular}

TSAT, transferrin saturation; PTH, parathyroid hormone; HDL, high density lipoprotein; spKt/V, single pool $\mathrm{Kt} / \mathrm{V}$; URR, urea reduction rate; nPNA, normalized protein nitrogen appearance rate; CRP, C-reactive protein; ERI, erythropoietin resistance index. 
$13.3 \pm 7.0 \mathrm{IU} / \mathrm{kg} / \mathrm{week} / \mathrm{g} / \mathrm{dl}$, respectively (Table 2).

Univariate analysis showed that ERI was significantly correlated with both body mass index (BMI) (coefficient $\beta$

Table 3. Correlation between the erythropoietin resistance index and various parameters.

\begin{tabular}{lcc}
\hline & $\begin{array}{c}\text { Standardized } \\
\text { coefficient } \beta\end{array}$ & $P$ \\
\hline Age (year) & 0.071 & 0.601 \\
Sex (male) & 0.191 & 0.154 \\
BMI $\left(\mathrm{kg} / \mathrm{m}^{2}\right)$ & -0.393 & 0.002 \\
Dialysis duration (year) & 0.109 & 0.421 \\
TSAT (\%) & -0.032 & 0.812 \\
Ferritin (ng/ml) & 0.173 & 0.199 \\
Albumin (g/dl) & 0.214 & 0.113 \\
Calcium (mg/dl) & 0.167 & 0.215 \\
Phosphorus (mg/dl) & -0.020 & 0.882 \\
PTH (pg/ml) & -0.157 & 0.249 \\
Total cholesterol (mg/dl) & -0.088 & 0.515 \\
HDL-cholesterol (mg/dl) & 0.009 & 0.947 \\
spKtV & 0.260 & 0.058 \\
nPNA (g/kg/day) & 0.136 & 0.342 \\
Resistin (log[ug/L]) & 0.332 & 0.018 \\
Adiponectin (Log [mg/L]) & -0.204 & 0.155 \\
CRP (Log[mg/L]) & -0.269 & 0.059 \\
Interleukin-6 (log[ng/mL]) & 0.159 & 0.270 \\
\hline
\end{tabular}

BMI, body mass index; TSAT, transferrin saturation; $\mathrm{PTH}$, parathyroid hormone; HDL, high density lipoprotein; spKt/V, single pool Kt/V; nPNA, normalized protein nitrogen appearance rate; $\mathrm{CRP}, \mathrm{C}$-reactive protein.
$=-0.393, p=0.002$ ) and serum levels of resistin (coefficient $\beta=0.332, p=0.018$ ) (Table 3 ). Serum resistin did not correlate with CRP (coefficient $\beta=-0.203, \mathrm{p}=0.176$ ) or IL-6 (coefficient $\beta=0.233, p=0.103$ ). The multiple regression analysis showed that BMI (coefficient $\beta=$ $-0.513, p<0.001$ ) and serum resistin (coefficient $\beta=0.314$, $p=0.017$ ) were significant independent determinants of EPO responsiveness (Table 4), while linear regression confirmed a correlation between ERI and resistin $\left(r^{2}=0.111, p\right.$ $=0.018)$ (Fig. 1).

\section{Discussion}

In patients with renal failure, EPO replacement is the mainstay of the anemia treatment. Therefore, in addition to their potential as prognostic indicators, EPO responsiveness and the achieved $\mathrm{Hb}$ values are strong predictors of mortality risk (Kilpatrick et al. 2008). EPO resistance in patients

Table 4. Multiple linear regression for independent factors associated with the erythropoietin resistance index.

\begin{tabular}{lcr}
\hline & $\begin{array}{c}\text { Standardized } \\
\text { coefficient } \beta\end{array}$ & $P$ \\
\hline Age (year) & -0.089 & 0.479 \\
Sex (male) & 0.193 & 0.118 \\
BMI $\left(\mathrm{kg} / \mathrm{m}^{2}\right)$ & -0.513 & $<0.001$ \\
$\mathrm{spKtV}$ & 0.041 & 0.739 \\
Resistin $(\log [\mathrm{ug} / \mathrm{L}])$ & 0.314 & 0.017 \\
CRP $(\log [\mathrm{mg} / \mathrm{L}])$ & -0.248 & 0.064 \\
\hline
\end{tabular}

BMI, body mass index; spKt/V, single pool Kt/V; CRP, $\mathrm{C}$-reactive protein.

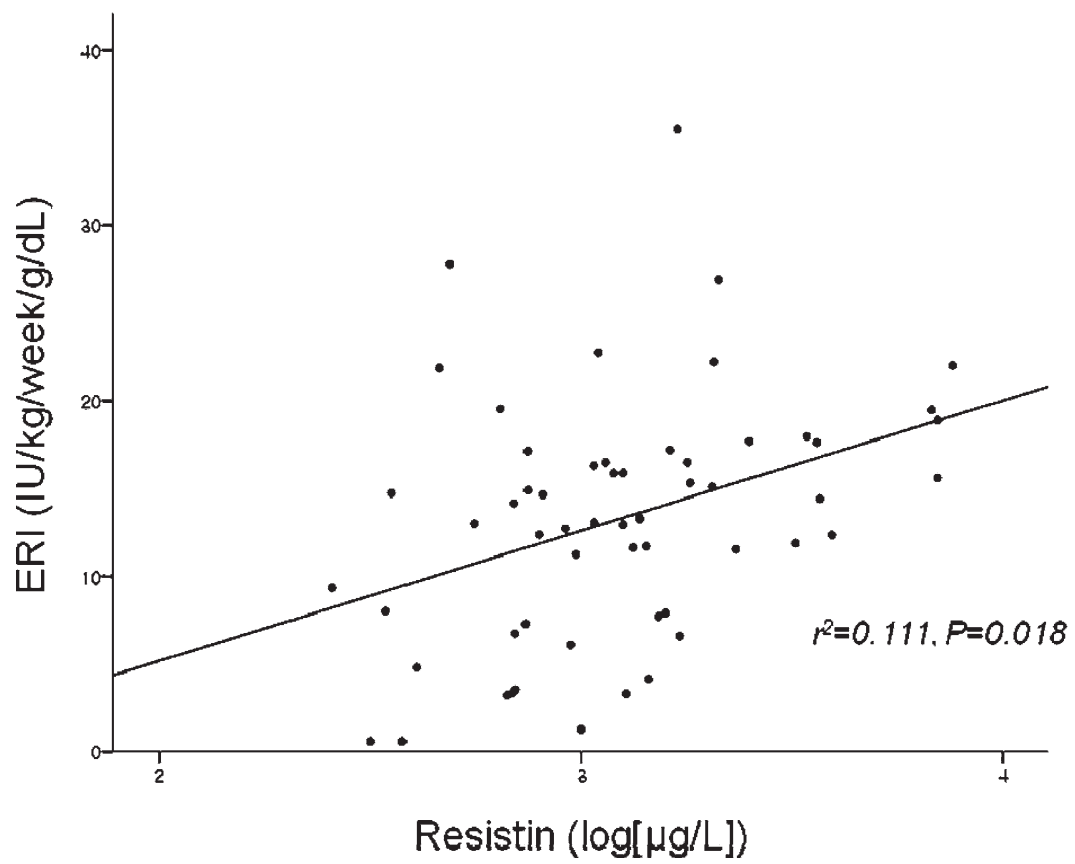

Fig. 1. Correlation between the erythropoietin resistance index (ERI) and serum resistin levels. Resistin levels in nondiabetic patients undergoing hemodialysis are positively correlated with the ERI $(n=57)$. 
with adequate iron stores is associated with concomitant inflammation or infection, severe hyperparathyroidism, aluminum intoxication, vitamin $\mathrm{B}_{12}$ or folate deficiencies, inadequate dialysis, and drug treatments (Lacombe 1996; Smrzova et al. 2005; Al-Hilali et al. 2007; Kaynar et al. 2007; Costa et al. 2008a; Locatelli et al. 2009). The variability in patient responsiveness to EPO, however, remains largely unexplained.

The main finding of this study is that serum resistin levels positively correlate with EPO responsiveness in nondiabetic HD patients. Previous studies demonstrated increased resistin concentrations in insulin resistant patients (Anderson et al. 2007; Mojiminiyi and Abdella 2007). The improvement of anemia by EPO reversed insulin resistance in uremic patients (Borissova et al. 1993; Mak 1996). EPO treatment may therefore participate in a reduction of insulin resistance through iron store depletion and an improvement of chronic inflammation in patients on maintenance HD (Rasic-Milutinovic et al. 2008). Thus, serum resistin levels may be related to EPO responsiveness through insulin resistance.

The role of the adipokine resistin in hematopoietic stem cell function is not well defined, and the potential implications of EPO responsiveness are not clear. Several lines of evidence indicate that resistin is related to erythropoiesis. First, resistin expression is higher in normal human fetal liver, adult bone marrow, umbilical cord blood, and peripheral blood cells, which indicates that the distribution of human resistin is correlated with normal haematopoiesis under certain conditions (Wu et al. 2009). Second, granulocyte colony-stimulating factor (G-CSF) induces the secretion of resistin by adipocytes in vitro, and serum resistin levels are significantly elevated by G-CSF treatment (Tanaka et al. 2009). A G-CSF dose-related effect may play a role in the inhibition of erythropoiesis and the worsening of anemia (Papaldo et al. 2006). Therefore, a link between the secretion of resistin and a decline in erythropoiesis, may exist, thus suggesting that resistin may be related to EPO responsiveness.

An inverse correlation between BMI and anemia control has been observed in HD patients (Takeda et al. 2002; Di Iorio et al. 2007), and BMI was independently associated with EPO responsiveness (Locatelli et al. 2006). In this study, a significant negative correlation between EPO responsiveness and BMI was observed. Kotanko et al. reported that EPO requirements and EPO resistance are reduced in patients with a high total body composition of adipose tissue and subcutaneous adipose tissue (Kotanko et al. 2008). More than 100 factors, including adipokines and cytokines are secreted from adipose tissue and these mediators may be related to EPO responsiveness. Adipose tissue is thought to be involved in energy regulation, inflammation, and the immune response, and adipocytes have been shown to be a part of the hematopoietic microenvironment.

Malyszko et al. reported an association between resistin and inflammatory markers in HD patients
(Malyszko et al. 2007). Resistin in humans is primarily produced by inflammatory cells, both inside and outside the adipose tissue (Steppan et al. 2001; Patel et al. 2003). Resistin release is associated with inflammation, is a common finding in HD patients, and is enhanced in EPO nonresponders compared to responders. However, unlike several previous studies that showed a strong association between CRP or IL-6 and EPO responsiveness (Axelsson et al. 2005), in this study, inflammatory cytokines such as CRP and IL-6 were not determinants of ERI. One possible explanation for this discrepancy is the differing populations investigated. The prevalence of inflammation in Asian communities including China and Korea are considered much lower as compared with the white dialysis cohorts (Noh et al. 1998; Stenvinkel et al. 2002; Wang et al. 2003). This may reflect differences in inflammatory responses or a genetic susceptibility to develop inflammation between Asian and white populations.

Our study has some limitations. First, we used only a small number of patients within one center that may display significant limitations. Secondly, we did not elucidate the mechanism of action underlying the association between resistin levels and EPO responsiveness. Further long-term follow-up of a larger number of patients is needed to clarity the relationship between resistin and EPO responsiveness.

In conclusion, we suggest that resistin is a novel marker of EPO responsiveness in HD patients. A key factor of anemia correction is EPO treatment; however, the causes of low responsiveness to EPO vary among HD patients, and few biomarkers to predict its responsiveness exist. Although inflammatory markers are good candidates, other mechanisms may exist independently of inflammation. We found that resistin levels were related to EPO responsiveness in nondiabetic HD patients, independent of IL- 6 and CRP. This may aid our understanding of the variable mechanisms of EPO responsiveness. Further studies are now required to form a direct relationship between resistin and EPO responsiveness.

\section{Conflict of Interest}

The authors have no financial conflict of interest.

\section{References}

Al-Hilali, N., Al-Humoud, H., Ninan, V.T., Nampoory, M.R., Puliyclil, M.A. \& Johny, K.V. (2007) Does parathyroid hormone affect erythropoietin therapy in dialysis patients? Med. Princ. Pract., 16, 63-67.

Anderson, P.D., Mehta, N.N., Wolfe, M.L., Hinkle, C.C., Pruscino, L., Comiskey, L.L., Tabita-Martinez, J., Sellers, K.F., Rickels, M.R., Ahima, R.S. \& Reilly, M.P. (2007) Innate immunity modulates adipokines in humans. J. Clin. Endocrinol. Metab., 92, 2272-2279.

Axelsson, J., Qureshi, A.R., Heimburger, O., Lindholm, B., Stenvinkel, P. \& Barany, P. (2005) Body fat mass and serum leptin levels influence epoetin sensitivity in patients with ESRD. Am. J. Kidney Dis., 46, 628-634.

Borissova, A.M., Djambazova, A., Todorov, K., Dakovska, L., Tankova, T. \& Kirilov, G. (1993) Effect of erythropoietin on 
the metabolic state and peripheral insulin sensitivity in diabetic patients on haemodialysis. Nephrol. Dial. Transplant., 8, 93.

Cohen, G. \& Horl, W.H. (2009) Resistin as a cardiovascular and atherosclerotic risk factor and uremic toxin. Semin. Dial., 22, 373-377.

Costa, E., Lima, M., Alves, J.M., Rocha, S., Rocha-Pereira, P., Castro, E., Miranda, V., do, S.F., Loureiro, A., Quintanilha, A., Belo, L. \& Santos-Silva, A. (2008a) Inflammation, T-cell phenotype, and inflammatory cytokines in chronic kidney disease patients under hemodialysis and its relationship to resistance to recombinant human erythropoietin therapy. $J$. Clin. Immunol., 28, 268-275.

Costa, E., Pereira, B.J., Rocha-Pereira, P., Rocha, S., Reis, F., Castro, E., Teixeira, F., Miranda, V., do Sameiro Faria, M., Loureiro, A., Quintanilha, A., Belo, L. \& Santos-Silva, A. (2008b) Role of prohepcidin, inflammatory markers and iron status in resistance to rhEPO therapy in hemodialysis patients. Am. J. Nephrol., 28, 677-683.

Di Iorio, B., Cirillo, M., Bellizzi, V., Stellato, D. \& De Santo, N.G. (2007) Prevalence and correlates of anemia and uncontrolled anemia in chronic hemodialysis patients - the Campania Dialysis Registry. Int. J. Artif. Organs, 30, 325-333.

Diez, J.J., Iglesias, P., Fernandez-Reyes, M.J., Aguilera, A., Bajo, M.A., Alvarez-Fidalgo, P., Codoceo, R. \& Selgas, R. (2005) Serum concentrations of leptin, adiponectin and resistin, and their relationship with cardiovascular disease in patients with end-stage renal disease. Clin. Endocrinol. (Oxf)., 62, 242-249.

Kanbay, M., Perazella, M.A., Kasapoglu, B., Koroglu, M. \& Covic, A. (2010) Erythropoiesis stimulatory agent- resistant anemia in dialysis patients: review of causes and management. Blood Purif., 29, 1-12.

Kaynar, K., Ozkan, G., Erem, C., Gul, S., Yilmaz, M., Sonmez, B., Ozdemir, F. \& Ulusoy, S. (2007) An unusual etiology of erythropoietin resistance: hyperthyroidism. Ren. Fail., 29, 759-761.

Kilpatrick, R.D., Critchlow, C.W., Fishbane, S., Besarab, A., Stehman-Breen, C., Krishnan, M. \& Bradbury, B.D. (2008) Greater epoetin alfa responsiveness is associated with improved survival in hemodialysis patients. Clin. J. Am. Soc. Nephrol., 3, 1077-1083.

Kotanko, P., Thijssen, S. \& Levin, N.W. (2008) Association between erythropoietin responsiveness and body composition in dialysis patients. Blood Purif., 26, 82-89.

Lacombe, C. (1996) Resistance to erythropoietin. N. Engl. J. Med., 334, 660-662.

Lago, F., Dieguez, C., Gomez-Reino, J. \& Gualillo, O. (2007) The emerging role of adipokines as mediators of inflammation and immune responses. Cytokine Growth Factor Rev., 18, 313325.

Locatelli, F., Andrulli, S., Memoli, B., Maffei, C., Del Vecchio, L., Aterini, S., De Simone, W., Mandalari, A., Brunori, G., Amato, M., Cianciaruso, B. \& Zoccali, C. (2006) Nutritional-inflammation status and resistance to erythropoietin therapy in haemodialysis patients. Nephrol. Dial. Transplant., 21, 991-998.

Locatelli, F., Covic, A., Eckardt, K.U., Wiecek, A. \& Vanholder, R. (2009) Anaemia management in patients with chronic kidney disease: a position statement by the Anaemia Working Group of European Renal Best Practice (ERBP). Nephrol. Dial. Transplant., 24, 348-354.

Mak, R.H. (1996) Correction of anemia by erythropoietin reverses insulin resistance and hyperinsulinemia in uremia. Am. J. Physiol., 270, F839-844.

Malyszko, J., Malyszko, J.S., Kozminski, P., Pawlak, K. \& Mysliwiec, M. (2007) Elevated resistin is related to inflammation and residual renal function in haemodialysed patients. Nephrology (Carlton), 12, 246-253.
Mojiminiyi, O.A. \& Abdella, N.A. (2007) Associations of resistin with inflammation and insulin resistance in patients with type 2 diabetes mellitus. Scand. J. Clin. Lab. Invest., 67, 215-225.

Noh, H., Lee, S.W., Kang, S.W., Shin, S.K., Choi, K.H., Lee, H.Y. \& Han, D.S. (1998) Serum C-reactive protein: a predictor of mortality in continuous ambulatory peritoneal dialysis patients. Perit. Dial. Int., 18, 387-394.

Papaldo, P., Ferretti, G., Di Cosimo, S., Giannarelli, D., Marolla, P., Lopez, M., Cortesi, E., Antimi, M., Terzoli, E., Carlini, P., Vici, P., Botti, C., Di Lauro, L., Naso, G., Nistico, C., Mottolese, M., Di Filippo, F., Ruggeri, E.M., Ceribelli, A. \& Cognetti, F. (2006) Does granulocyte colony-stimulating factor worsen anemia in early breast cancer patients treated with epirubicin and cyclophosphamide? J. Clin. Oncol., 24, 3048-3055.

Patel, L., Buckels, A.C., Kinghorn, I.J., Murdock, P.R., Holbrook, J.D., Plumpton, C., Macphee, C.H. \& Smith, S.A. (2003) Resistin is expressed in human macrophages and directly regulated by PPAR gamma activators. Biochem. Biophys. Res. Commun., 300, 472-476.

Rasic-Milutinovic, Z., Perunicic-Pekovic, G., Cavala, A., Gluvic, Z., Bokan, L. \& Stankovic, S. (2008) The effect of recombinant human erythropoietin treatment on insulin resistance and inflammatory markers in non-diabetic patients on maintenance hemodialysis. Hippokratia, 12, 157-161.

Regidor, D.L., Kopple, J.D., Kovesdy, C.P., Kilpatrick, R.D., McAllister, C.J., Aronovitz, J., Greenland, S. \& KalantarZadeh, K. (2006) Associations between changes in hemoglobin and administered erythropoiesis-stimulating agent and survival in hemodialysis patients. J. Am. Soc. Nephrol., 17, 1181-1191.

Smrzova, J., Balla, J. \& Barany, P. (2005) Inflammation and resistance to erythropoiesis-stimulating agents - what do we know and what needs to be clarified? Nephrol. Dial. Transplant., 20 Suppl 8, viii2-7.

Stenvinkel, P., Wanner, C., Metzger, T., Heimburger, O., Mallamaci, F., Tripepi, G., Malatino, L. \& Zoccali, C. (2002) Inflammation and outcome in end-stage renal failure: does female gender constitute a survival advantage? Kidney Int., 62, 1791-1798.

Steppan, C.M., Bailey, S.T., Bhat, S., Brown, E.J., Banerjee, R.R., Wright, C.M., Patel, H.R., Ahima, R.S. \& Lazar, M.A. (2001) The hormone resistin links obesity to diabetes. Nature, $\mathbf{4 0 9}$, 307-312.

Takeda, A., Toda, T., Shinohara, S., Mogi, Y. \& Matsui, N. (2002) Factors contributing to higher hematocrit levels in hemodialysis patients not receiving recombinant human erythropoietin. Am. J. Kidney Dis., 40, 104-109.

Tanaka, Y., Yujiri, T., Tanaka, M., Mitani, N., Tanimura, A. \& Tanizawa, Y. (2009) Alteration of adipokines during peripheral blood stem cell mobilization induced by granulocyte colony-stimulating factor. J. Clin. Apher, 24, 205-208.

Wang, A.Y., Woo, J., Lam, C.W., Wang, M., Sea, M.M., Lui, S.F., Li, P.K. \& Sanderson, J. (2003) Is a single time point C-reactive protein predictive of outcome in peritoneal dialysis patients? J. Am. Soc. Nephrol., 14, 1871-1879.

Wu, T., Ren, G.P., Xu, T., Zhang, W., Gao, Z.Q., Yan, S.J., Hong, L.J., Zhao, H.L. \& Li, D.S. (2009) Correlation of human resistin gene expression with leukemia incidence. Zhongguo Shi Yan Xue Ye Xue Za Zhi, 17, 1149-1153 (in Chinese).

Zhang, Y., Thamer, M., Stefanik, K., Kaufman, J. \& Cotter, D.J. (2004) Epoetin requirements predict mortality in hemodialysis patients. Am. J. Kidney Dis., 44, 866-876.

Ziegelmeier, M., Bachmann, A., Seeger, J., Lossner, U., Kratzsch, J., Bluher, M., Stumvoll, M. \& Fasshauer, M. (2008) Adipokines influencing metabolic and cardiovascular disease are differentially regulated in maintenance hemodialysis. Metabolism, 57, 1414-1421. 